\title{
Meta-analyses of treatment standards for pancreatic cancer (Review)
}

\author{
JUN GONG $^{1}$, RICHARD TULI $^{2}$, ARVIND SHINDE $^{3}$ and ANDREW E. HENDIFAR ${ }^{4}$ \\ Departments of ${ }^{1}$ Internal Medicine, ${ }^{2}$ Radiation Oncology and ${ }^{3}$ Hematology and Oncology; ${ }^{4}$ Gastrointestinal \\ and Neuroendocrine Malignancies, Samuel Oschin Cancer Center, Cedars-Sinai Medical Center, Los Angeles, CA 90048, USA
}

Received April 3, 2015; Accepted November 23, 2015

DOI: $10.3892 / \mathrm{mco} .2015 .716$

\begin{abstract}
Pancreatic cancer is the most lethal common cancer with an estimated 5-year survival rate of 6-7\% (across all stages). The only potential curative therapy is surgical resection in those with localized disease. Adjuvant (postoperative) therapy confers a survival advantage over postoperative observation alone. Neoadjuvant (preoperative) therapy offers the potential to downstage initially unresectable tumors for resection, sterilize resection margins and decrease locoregional recurrence, and identify a subset of patients with aggressive disease for whom surgery will not be beneficial. Induction chemotherapy followed by consolidation chemoradiation is another recommended approach in those with locally advanced disease. For those who cannot be downstaged, cannot tolerate surgery, or were diagnosed with metastatic disease, treatment remains palliative with chemotherapy being a critical component of this approach. Recently, intensive combination chemotherapy has been shown to improve survival rates in comparison to gemcitabine alone in advanced disease. The past few decades have afforded an accumulation of high-level evidence regarding neoadjuvant, adjuvant and palliative therapies in pancreatic cancer. There are numerous reviews discussing recent retrospective studies, prospective studies and randomized controlled trials in each of these areas. However, reviews of optimal and recommended treatment strategies across all stages of pancreatic cancer that focus on the highest levels of hierarchical evidence, such as meta-analyses, are limited. The discussion of novel therapeutics is beyond the scope of this review. However, an extensive and the most current collection of meta-analyses of first-line systemic and locoregional treatment options for all stages of pancreatic cancer to date has been accumulated.
\end{abstract}

Correspondence to: Dr Andrew E. Hendifar, Gastrointestinal and Neuroendocrine Malignancies, Samuel Oschin Cancer Center, Cedars-Sinai Medical Center, 8700 Beverly Boulevard, AC 1042, Los Angeles, CA 90048, USA

E-mail: Andrew.Hendifar@cshs.org

Key words: pancreatic cancer, meta-analysis, neoadjuvant, adjuvant, palliative

\section{Contents}

1. Introduction

2. Localized and resectable pancreatic cancer (stage I or II)

3. Borderline resectable and locally advanced pancreatic cancer (stage III)

4. Advanced and metastatic pancreatic cancer (stage IV)

5. Conclusion

\section{Introduction}

Epidemiology. Although pancreatic cancer represents only $2.8 \%$ of all new cancer cases in the US, it is the fourth leading cause of cancer fatality in men and women (1). Of the estimated 48,960 new cases of pancreatic cancer in the U.S. in 2015, an estimated 40,560 are expected to succumb to the disease (2). Worldwide, pancreatic cancer is the eighth and ninth leading cause of cancer fatality in men and women, respectively, with an incidence of $2-8$ cases per 100,000 people and a greater predilection in men and developed countries (3). Accounting for $85 \%$ of all types of pancreatic cancer, pancreatic ductal adenocarcinoma (PDAC) is often synonymous with pancreatic cancer and tends to occur more in the elderly (median age of 71 years at diagnosis) and at an advanced stage $(<20 \%$ present with localized and resectable disease) $(4,5)$. In total, 60-70 and $20-25 \%$ of pancreatic cancers occur in the head and body/tail of the pancreas, respectively, with symptoms and signs related to the location (5).

\section{Localized and resectable pancreatic cancer (stage I or II)}

Surgery. The only potential curative therapy for pancreatic cancer remains surgical resection in the $15-20 \%$ of cases meeting criteria for localized and resectable disease (stage I or II) following diagnosis (4-6). In particular, pancreaticoduodenectomy (the Whipple procedure) with standard lymphadenectomy and distal pancreatectomy with splenectomy are the surgeries of choice for cancers of the head/neck and body/tail, respectively (4-6). The median survival is 17-27 months in those with resected pancreatic cancer with 5 -year survival rates of $15-20 \%(7,8)$. However, of the $15-20 \%$ of candidates who undergo surgical resection, 66-92\% 
experience disease recurrence within 2 years of resection with local recurrence rates of $35-60 \%$ and systemic recurrence rates as high as $80-90 \%(8,9)$.

Adjuvant therapy. Adjuvant (postoperative) therapy in the form of chemotherapy or chemoradiotherapy has been shown to confer a survival advantage compared to postoperative observation alone (10-18). Meta-analyses of trials involving gemcitabine or 5-fluorouracil (5-FU)-based regimens show that adjuvant chemotherapy, when compared to postoperative observation alone, significantly improves survival [as much as 7 months in increased median overall survival (OS)] in those with negative-margin (R0) resections, although this effect is less pronounced in those with microscopically positive-margin (R1) resections (19-24). Following adjustment for confounding factors, adjuvant therapy with gemcitabine or 5-FU again provided an OS benefit over observation alone with hazard ratios (HRs) of 0.59 [95\% confidence interval (CI), 0.41-0.83] and 0.65 (95\% CI, 0.49-0.84), respectively (22). Significant differences in survival were not observed when comparing adjuvant gemcitabine and 5-FU arms (22). Results are more conflicting for adjuvant chemoradiotherapy as a majority of meta-analyses reveal that chemoradiation does not significantly confer a survival advantage over upfront surgery alone or those not receiving adjuvant chemoradiation, although it may provide a small survival benefit in those with R1 resections (Table I) $(19,21,22,24-26)$. One meta-analysis was the first to use Bayesian analysis to demonstrate that adjuvant chemoradiation \pm chemotherapy incurs greater toxicity yet does not confer a survival advantage compared to adjuvant gemcitabine or 5-FU alone (22).

Although the role of radiotherapy as a component of adjuvant therapy remains controversial, 6 weeks of 5-FU-based chemoradiation preceded, followed by maintenance chemotherapy remains an acceptable alternative form of adjuvant therapy $(7,8,18,27,28)$. As thought previously, radiotherapy may further benefit a subset of patients undergoing R1 resections or at increased risk of locoregional recurrence $(7,8)$. Currently, 6 months of adjuvant chemotherapy with gemcitabine or 5-FU remains the standard for adjuvant therapy in those with resected pancreatic cancer $(8,13,29,30)$. Current trends in the treatment of resected pancreatic cancer in the US reflect on the recent publications of landmark trials as the use of adjuvant chemotherapy alone increased $<250 \%$, while the use of adjuvant chemoradiation decreased as much as $42 \%$, although chemoradiotherapy remains in slightly greater use compared to chemotherapy for adjuvant therapy (31). Furthermore, although early initiation of postoperative chemotherapy was once emphasized, it has now been demonstrated that completion of all 6 cycles of adjuvant therapy, rather than time to initiation of therapy, is critical to the survival outcome, as no differences in outcome were observed in those in which adjuvant chemotherapy was delayed $<12$ weeks $(32,33)$. Of note, a recent phase III trial failed to show significant differences in survival between adjuvant 5 -FU with folinic acid and adjuvant chemoradiation including 5-FU, cisplatin, and interferon $\alpha-2 b$, while a Japan-based phase III trial showed that adjuvant $\mathrm{S}-1$, an oral fluoropyrimidine, was superior to adjuvant gemcitabine, although metabolic differences between Asian and Caucasian ethnicities limit its application in the West for resected pancreatic cancer (34-36).
Neoadjuvant therapy. Evidence suggests that neoadjuvant (preoperative) therapy in localized pancreatic cancer (LPC) may improve rates of $\mathrm{R} 0$ resections, decrease locoregional recurrence, and identify a subset of patients (on restaging) with aggressive disease for whom surgery will not provide a survival benefit $(4,7,8,37)$. Although $\sim 25 \%$ of those who undergo upfront surgery for localized disease are unable to complete adjuvant therapy, neoadjuvant therapy ensures that almost all can receive some form of treatment, although it carries the risk of disease progression in delaying potentially curative resection $(7,38,39)$. Neoadjuvant therapy with chemotherapy alone or predominantly 5-FU or gemcitabine-based chemoradiation \pm preceding chemotherapy followed by resection offers survival rates that compare favorably to those observed with resection followed by adjuvant therapy (Table II) (37-41). Despite higher rates of perioperative mortality, neoadjuvant therapy followed by resection demonstrates superior cost-effectiveness with postoperative morbidity and mortality rates that are comparable to those observed with upfront surgery for LPC $(42,43)$. Neoadjuvant therapy represents a rational alternative to a 'surgery-first' approach to LPC; however, is considered investigational due to the lack of complete and definitive data from phase III trials $(8,44)$. There are ongoing phase III trials involving neoadjuvant therapy followed by surgery versus upfront surgery with adjuvant therapy and neoadjuvant therapy with adjuvant therapy versus adjuvant therapy alone (https://clinicaltrials.gov/).

\section{Borderline resectable and locally advanced pancreatic cancer (stage III)}

Neoadjuvant therapy.Approximately $30 \%$ of patients diagnosed with pancreatic cancer have locally advanced and unresectable disease (stage III) with a median survival of 8-12 months and 5 -year survival rate of $\sim 6 \%(4,7,45)$. Neoadjuvant therapy can potentially downstage tumors to increase $\mathrm{R} 0$ resection rates in a subset of patients with 'borderline resectable' disease, as well as downstage those with locally advanced disease for possible resection $(7,8,45,46)$. In those with initially unresectable disease (borderline resectable/locally advanced), neoadjuvant therapy with chemotherapy alone or, more commonly, 5-FU or gemcitabine-based chemoradiation \pm preceding induction chemotherapy \pm sequential chemotherapy has produced, for the most part, resectability rates of $30-40 \%$ (although with higher perioperative morbidity and mortality rates compared to initially resectable tumor patients) and, when followed by surgery, survival times within the range of those observed with upfront surgery followed by adjuvant therapy for initially resectable disease (Table II) (38-40,47-49).

In borderline resectable disease, a majority of retrospective and prospective studies using variations of gemcitabine-based chemotherapy alone or gemcitabine, capecitabine, or 5-FU-based chemoradiation \pm induction chemotherapy, have demonstrated resectability rates with high probability for $\mathrm{R} 0$ resections and survival times comparable to those in the meta-analyses described previously (Table II) $(50,51)$. Some, however, have argued that radiographic downstaging following neoadjuvant therapy is uncommon in borderline resectable disease, despite high rates of $\mathrm{R} 0$ resections achieved in patients without evidence of radiographic response. Therefore, it has 


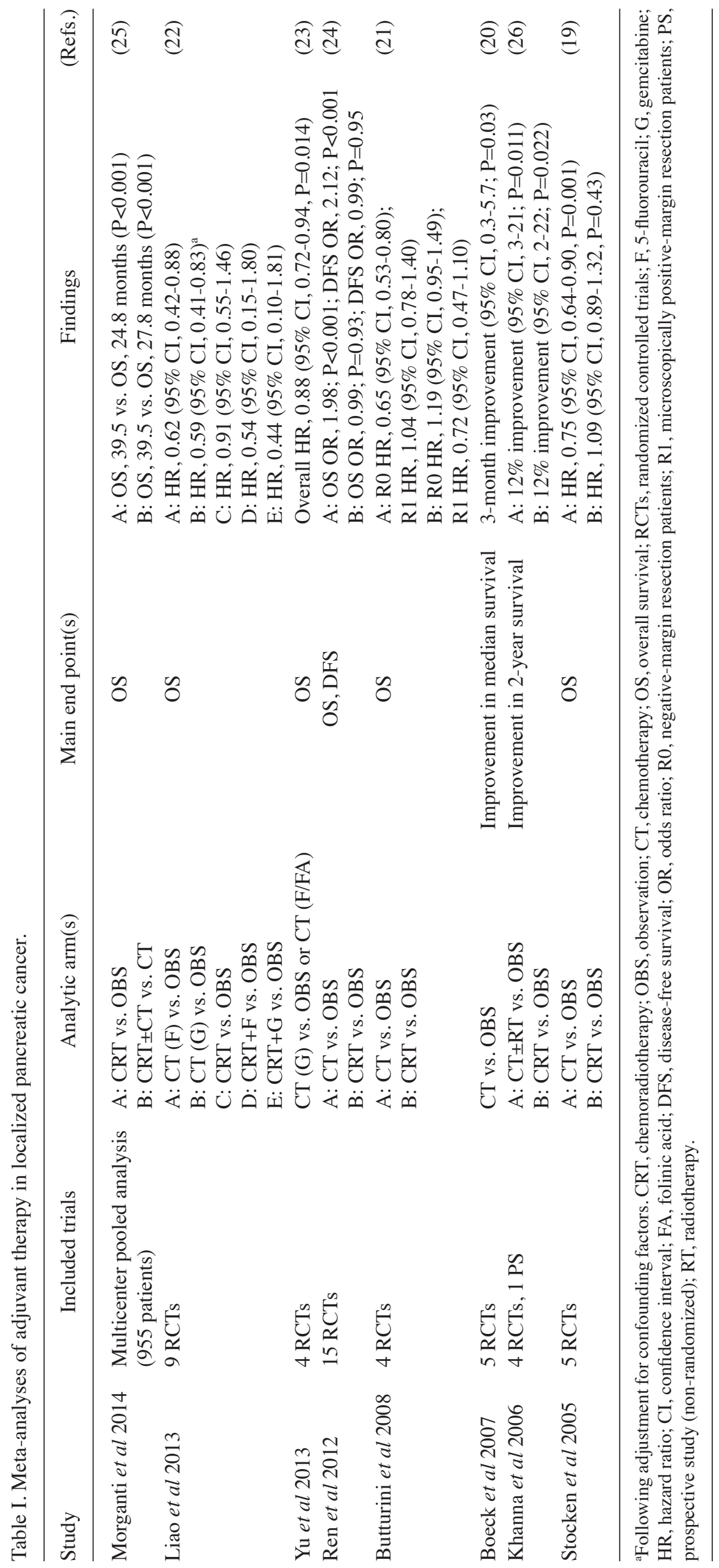




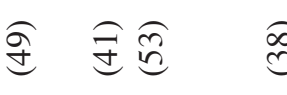

$\stackrel{\infty}{\stackrel{9}{+}}$

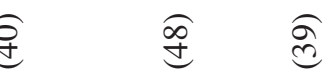

导

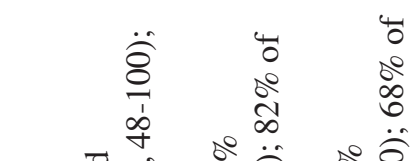

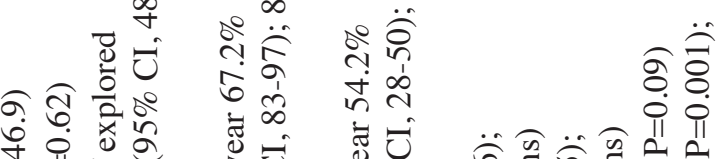

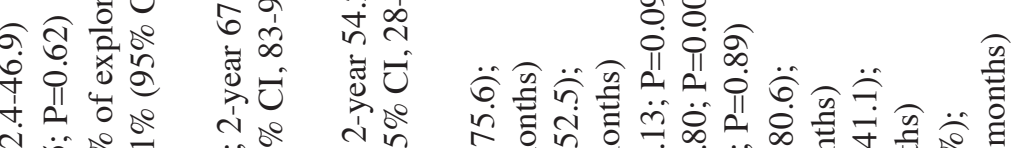

药 तंच $\infty$ o 0 के

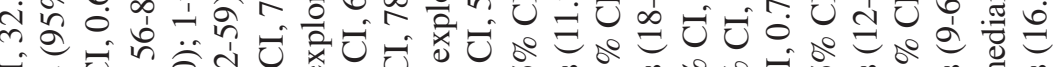

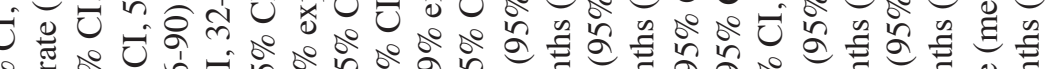

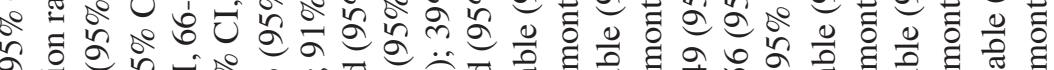

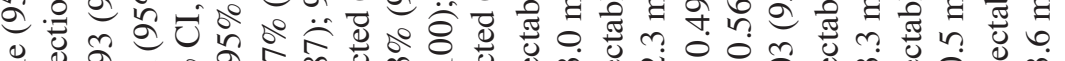

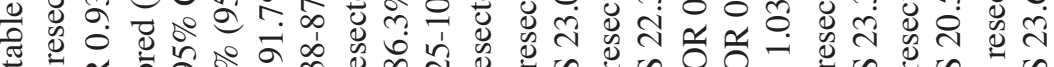

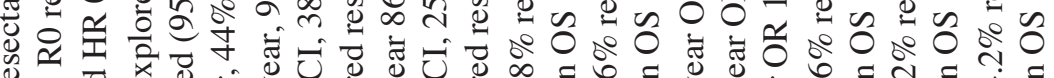

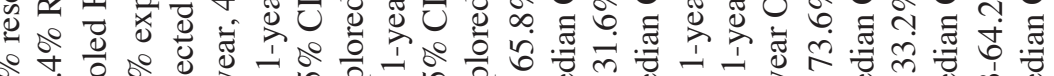

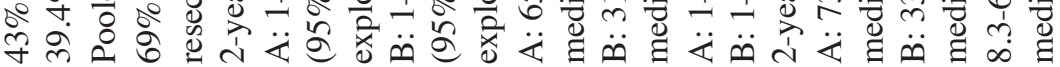

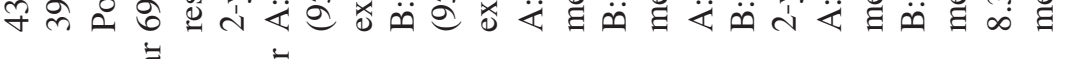
离 离

ปे.

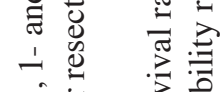

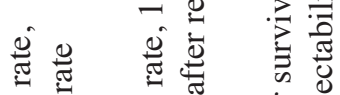

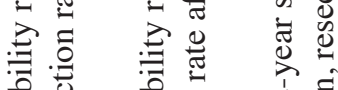

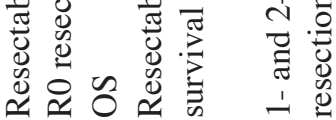

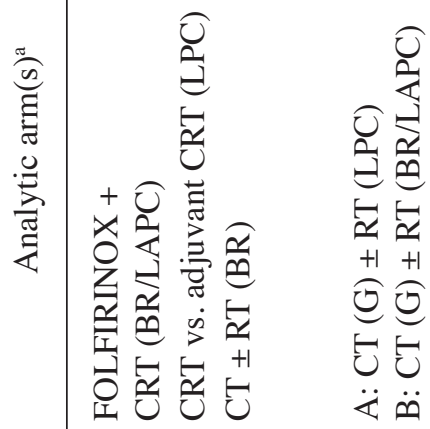

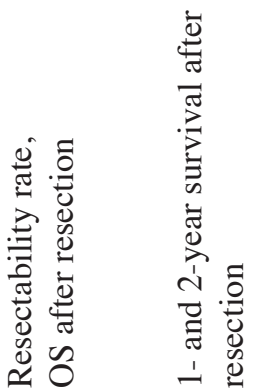

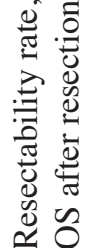

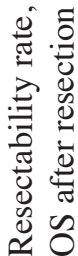

包这

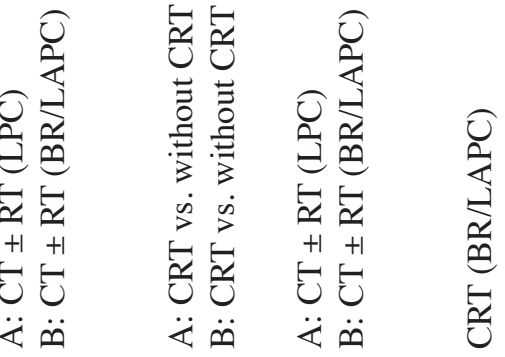

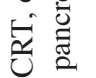

范

근

ํํํ

हี

离

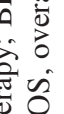

웜

ปे

过

这

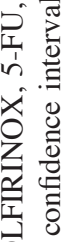

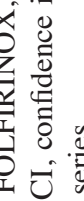

总 菂

萢

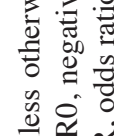

品

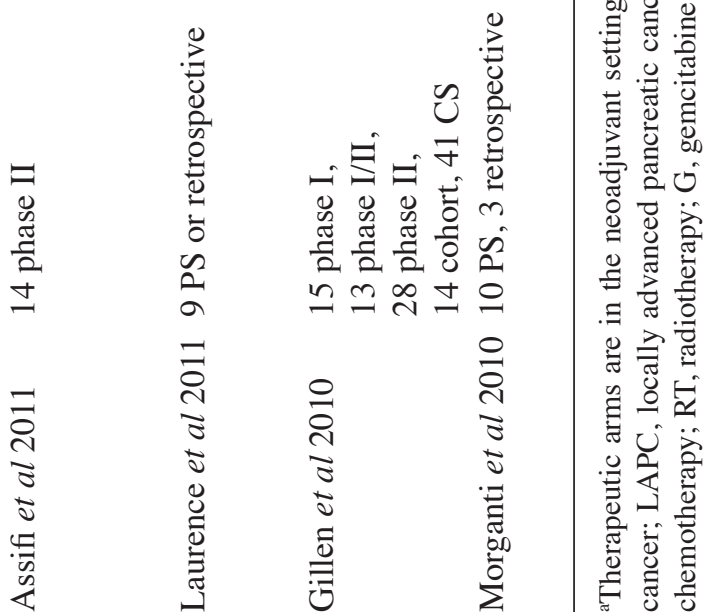


been proposed that resection should proceed following neoadjuvant therapy in the absence of disease progression or a decline in performance status (PS) $(52,53)$. Regardless, neoadjuvant therapy, ideally in the context of a clinical trial, is now recommended for borderline resectable disease in the absence of treatment criteria that has yet to be clearly defined (8). Recently, more intensive neoadjuvant regimens involving induction gemcitabine/nab-paclitaxel or 5-FU, leucovorin, irinotecan and oxaliplatin (FOLFIRINOX) have been used $(5,37,54)$. In particular, induction FOLFIRINOX \pm chemoradiation followed by surgery has shown a significantly increased survival rate compared to those with locally advanced/borderline resectable disease who received no neoadjuvant therapy (55). The ongoing Alliance A021101 multi-institutional trial (NCT01821612) using induction modified FOLFIRINOX (mFOLFIRNOX) and chemoradiotherapy followed by resection and adjuvant therapy will attempt to standardize a uniform definition of borderline resectable PDAC and criteria for assessing treatment efficacy.

Systemic and locoregional therapy. Low quality evidence from meta-analyses suggests that surgical resection appears to improve survival, decrease the length of hospital stay, and decrease costs compared to palliative treatment in select patients with locally advanced pancreatic cancer (LAPC) with venous involvement (56). Despite more aggressive approaches, such as pancreatectomy with arterial reconstruction (AR), having demonstrated improved survival over those without resection, higher perioperative morbidity/mortality rates and poorer long-term survival were observed with pancreatectomy + AR compared to pancreatectomy with venous reconstruction in those with LAPC (57). However, chemotherapy remains a critical component of the treatment approach for attempting to downstage locally advanced disease or palliative treatment of tumors that cannot be downstaged and resected, or those for which surgery is not an option. Early evidence demonstrated that chemotherapy (5-FU-based) improves survival compared to best supportive care alone, although 5-FU-based combination chemotherapy did not result in an increased survival compared to 5-FU alone in advanced pancreatic cancer (APC) (58). Gemcitabine widely became regarded as the preferred first-line therapy in APC due to its superiority over 5-FU (as discussed in the following) (59). A majority of meta-analyses on gemcitabine in combination with various agents, such as platinums, anthracyclines, camptothecin analogs, fluoropyrimidines, taxanes and molecular-targeted agents (MTAs), have since shown that gemcitabine-based combination therapy, in general, often results in greater toxicity yet appears to significantly improve OS, progression-free survival (PFS), and/or overall response rates (ORRs) compared to gemcitabine monotherapy in locally advanced/metastatic pancreatic cancer (Table III) $(58,60-73)$.

Subgroup and pooled analyses further reveal that gemcitabine + fluoropyrimidine (particularly capecitabine) and gemcitabine + platinum combinations represent the gemcitabine-based doublets providing the most consistent survival benefits over gemcitabine alone (58,63-73). Of note, gemcitabine + cisplatin appears to offer little to no significant survival benefits versus gemcitabine monotherapy, although others have contended this claim $(61,65,68,70,72,73)$. In addition, gemcitabine + camptothecin analog appears to only improve the ORR over single-agent gemcitabine (65). Although one subgroup analysis showed that gemcitabine + MTAs was the only combination resulting in a significant improvement in 6-month survival over gemcitabine alone, a number of meta-analyses have produced inadequate results with the exception of epidermal growth factor receptor (EGFR) inhibitors, such as erlotinib (discussed in the following) in locally advanced/metastatic disease $(63,65,73-78)$. S-1 has been studied extensively in Japanese patients with pancreatic cancer (79-81). In the locally advanced setting, there is conflicting data to support the use of S-1 in combination with gemcitabine. Consensus remains that this is an active agent for Asian patients; however, it requires further validation prior to adoption in the US as pharmacogenomic differences between ethnicities have been noted and may explain the varying reports of efficacy and toxicity of S-1 and other 5-FU based drugs (73).

In LAPC, survival trends favor gemcitabine-based combination regimens over gemcitabine alone (82). Combination therapy appears to have its greatest effects on survival in those with good PS [Eastern Cooperative Oncology Group (ECOG) scores of 0-1]; however, is relatively ineffective or even harmful in those with poor PS $(\mathrm{ECOG} \geq 2)(68,70,72)$.

Due to the survival benefits demonstrated in borderline resectable/LAPC and metastatic pancreatic cancer (MPC), intensive regimens, such as FOLFIRINOX or gemcitabine/nab-paclitaxel, are now being recommended in those with good PS (ECOG 0-1), while gemcitabine monotherapy remains the mainstay of therapy in those with poor PS (ECOG $\geq 2)$; the National Comprehensive Cancer Network, however, states gemcitabine monotherapy as an acceptable option in those with good PS and LAPC (55,83-85). There are still no phase III trials comparing FOLFIRINOX to gemcitabine/nab-paclitaxel in LAPC. Other meta-analyses have addressed gemcitabine dosing, delivery of chemotherapy (intra-arterial versus venous), and innovative ablative therapies as additional avenues of clinical benefit in LAPC/APC (86-89).

The role of chemoradiation in the management of LAPC remains controversial. Key trials involving chemoradiotherapy have produced mixed results with regards to survival advantage versus standard therapies in LAPC/APC (90-96). Chemoradiation confers a survival advantage over best supportive care alone or radiotherapy alone; however, it is more toxic (97-99). Furthermore, meta-analyses demonstrate that primarily 5-FU or gemcitabine-based chemoradiotherapy \pm prior induction chemotherapy \pm maintenance chemotherapy offers comparable or even superior survival times compared to chemotherapy alone, although often with greater toxicities in LAPC (Table III) (97-101). Notably, one analysis showed better survival with gemcitabine-based chemoradiation compared to 5-FU-based chemoradiation, although other studies have argued that capecitabine or 5-FU are the preferred radiosensitizers in LAPC $(84,98,102)$. Upfront chemoradiotherapy initially lost acceptability with the FFCD/SFRO trial when induction $5-\mathrm{FU}+$ cisplatin chemoradiation followed by maintenance gemcitabine showed inferior survival and greater toxicity compared to gemcitabine alone (96). However, several 


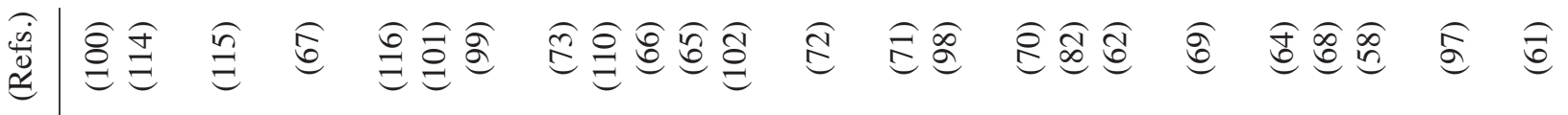

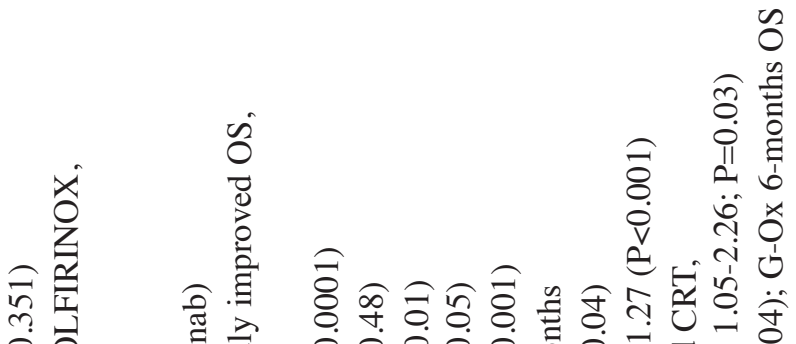

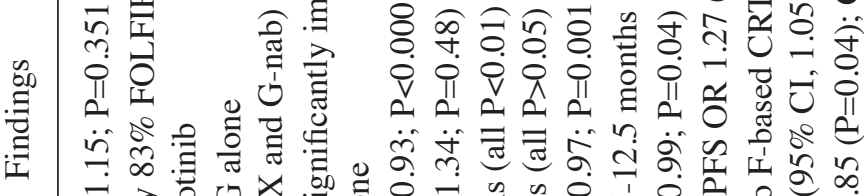

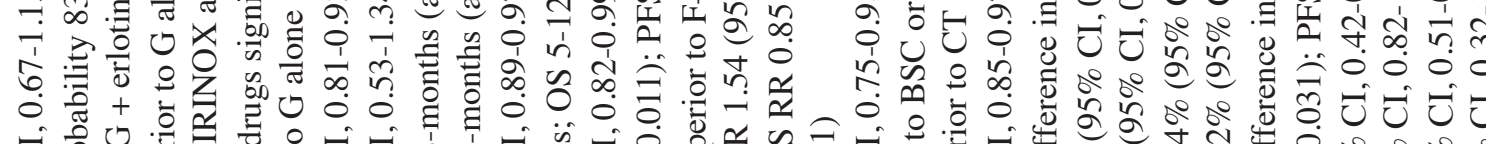

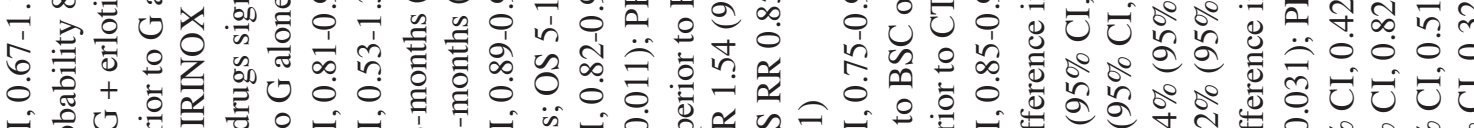

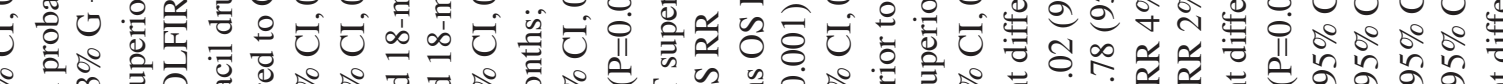

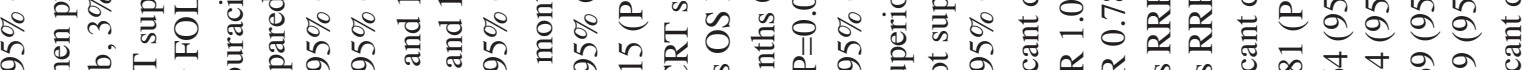

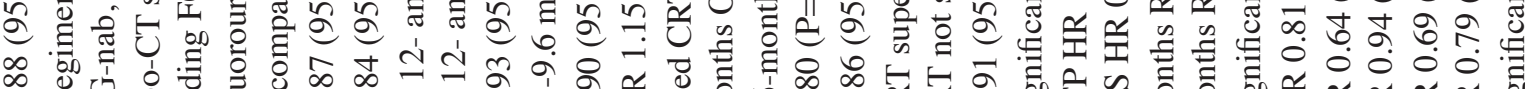

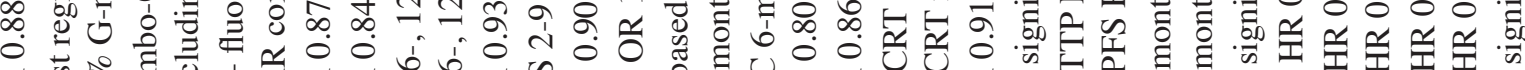

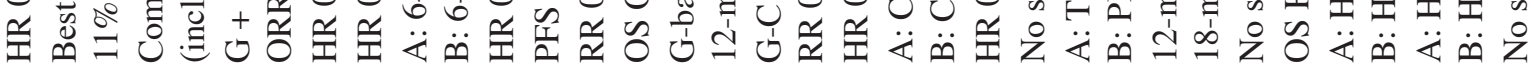

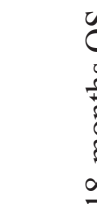

$$
\text { ठ }
$$

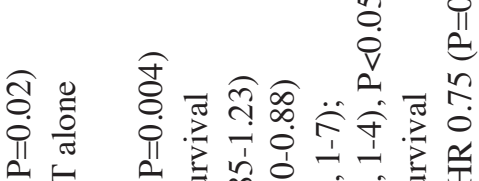
ir 
studies revealed that induction gemcitabine-based chemotherapy followed by consolidation 5-FU, capecitabine or gemcitabine-based chemoradiation, when there was no evidence of disease progression after 2 months of initial chemotherapy, provided favorable survival outcomes (even greater than in those who received chemoradiation or chemotherapy alone) in LAPC (103-105).

The rationale for this approach is associated with the fact that $\sim 30 \%$ of those with LAPC have occult metastatic disease at diagnosis, and induction chemotherapy can identify the subset of patients without metastatic disease who can benefit from locoregional control or those with aggressive disease who can be spared from resection and the toxicities of chemoradiotherapy $(84,85)$. Ultimately, radiotherapy alone or upfront chemoradiotherapy is not recommended as standard treatment for LAPC, although upfront chemoradiotherapy is an option in those with poorly controlled pain, bleeding or local obstruction $(84,85)$. Consolidation chemoradiation remains a recommended option for those with LAPC and good PS without evidence of disease progression following 2-6 cycles or 3-4 months of induction chemotherapy, despite preliminary results from the phase III LAP 07 study indicating no survival benefit with additional chemoradiation after induction gemcitabine compared to chemotherapy alone $(84-85,106)$. Modern radiotherapy techniques with concurrent chemotherapy also represent a relatively cost-effective strategy in improving clinical outcomes in LAPC (107).

\section{Advanced and metastatic pancreatic cancer (stage IV)}

Systemic therapy. The remaining $~ 50 \%$ of patients with pancreatic cancer present with advanced or metastatic disease (stage IV) with a median survival of 4-6 months and approximate 5-year survival rates of $1-2 \%(1,4,45)$. Treatment remains palliative for this group with gemcitabine having been the mainstay of therapy for the majority of the late 1990s and early 2000s; gemcitabine remains the first-line therapy in those with poor PS and MPC. For the last 3 decades of the 20th century, 5-FU was superior to best supportive care (108). A seminal trial in 1997 indicated a superior clinical benefit and a survival advantage with gemcitabine (median OS, 5.65 months) compared to 5-FU (median OS, 4.41 months, $\mathrm{P}=0.0025$ ) in APC (59). In 2007, gemcitabine/erlotinib showed a small survival benefit leading to Food and Drug Administration approval of its use in APC $(109,110)$. Again, S-1 alone proved to be noninferior to gemcitabine alone in an Asian-based phase III trial (111). More recently, FOLFIRINOX and gemcitabine/nab-paclitaxel both independently conferred significant survival advantages over gemcitabine alone $(112,113)$. Meta-analyses suggest that FOLFIRINOX and gemcitabine/nab-paclitaxel have the highest probabilities for being the two best regimens in terms of OS and PFS for APC, despite their increased risk for greater toxicities (Table III) (114-116). FOLFIRINOX demonstrates favorable cost-effectiveness and greater quality adjusted life-years compared to gemcitabine as first-line therapy (117). FOLFIRINOX and gemcitabine/nab-paclitaxel appear to have changed the standard of care, at least in those with good PS, as 2-year survival rates are now approaching $10 \%$ for either agent in advanced/metastatic disease-survival rates that were rarely observed previously (5). 


\section{Conclusion}

Pancreatic cancer remains the most lethal of the common cancers with a 5-year survival rate across all stages of $\sim 6.7 \%$ (1). Meta-analyses confirm that adjuvant gemcitabine or 5-FU improves survival compared to surgery alone and remains the standard for adjuvant therapy in resected pancreatic cancer. Although the benefits from the addition of radiation therapy in the adjuvant setting are under debate, 5-FU-based or gemcitabine-based chemoradiation preceded or followed by $5-\mathrm{FU} /$ leucovorin or gemcitabine remains an acceptable alternative form of adjuvant therapy in resected pancreatic cancer. Meta-analyses demonstrate high rates of resectability with neoadjuvant therapy (FOLFIRINOX \pm chemoradiation) in those with borderline resectable disease, although treatment criteria has yet to be clearly defined in this group. When applicable, neoadjuvant therapy in the context of a clinical trial is recommended for borderline resectable pancreatic cancer. For locally advanced and unresectable disease, meta-analyses confirm the benefits of combination chemotherapy over single-agent chemotherapy. FOLFIRINOX or gemcitabine with nab-paclitaxel are now being recommended in those with good PS while gemcitabine alone is recommended in those with poor PS in LAPC. Induction chemotherapy followed by chemoradiotherapy remains an option in certain patients with LAPC. In stage IV disease, meta-analyses confirm the survival benefits offered by FOLFIRINOX or gemcitabine with nab-paclitaxel compared to gemcitabine alone and are now treatment standards in those with good PS. Gemcitabine remains an option in patients with metastatic pancreatic cancer and poor PS. Despite the poor prognosis, development of novel therapeutic agents, advancements in diagnosis and prevention, and improvements in multidisciplinary care are underway in order to enhance outcomes in this area $(4,5,7)$. Improved survival is currently being observed postoperatively and in advanced/metastatic disease with greater implementation of adjuvant and intensive multi-agent therapies, respectively. However, the results from ongoing clinical trials covering all stages of management in pancreatic cancer, including neoadjuvant, adjuvant and palliative therapy, are anticipated.

\section{References}

1. Howlader N, Noone AM, Krapcho M, Garshell J, Neyman N, Altekruse SF, et al (eds): SEER Cancer Statistics Review, 1975-2011, National Cancer Institute. Bethesda, MD. http://seer. cancer.gov/csr/1975_2011/.2014. Accessed March 21, 2015.

2. Siegel RL, Miller KD and Jemal A: Cancer statistics, 2015. CA Cancer J Clin 65: 5-29, 2015

3. Jemal A, Bray F, Center MM, Ferlay J, Ward E and Forman D: Global cancer statistics. CA Cancer J Clin 61: 69-90, 2011.

4. Hidalgo M: Pancreatic cancer. N Engl J Med 362: 1605-1617, 2010.

5. Ryan DP, Hong TS and Bardeesy N: Pancreatic adenocarcinoma. N Engl J Med 371: 1039-1049, 2014.

6. Evans DB, Farnell MB, Lillemoe KD, Vollmer C Jr, Strasberg SM and Schulick RD: Surgical treatment of resectable and borderline resectable pancreas cancer: Expert consensus statement. Ann Surg Oncol 16: 1736-1744, 2009.

7. Wolfgang CL, Herman JM, Laheru DA, Klein AP, Erdek MA, Fishman EK and Hruban RH: Recent progress in pancreatic cancer. CA Cancer J Clin 63: 318-348, 2013.

8. Abrams RA, Lowy AM, O'Reilly EM, Wolff RA, Picozzi VJ and Pisters PW: Combined modality treatment of resectable and borderline resectable pancreas cancer: Expert consensus statement. Ann Surg Oncol 16: 1751-1756, 2009.
9. Castellanos JA and Merchant NB: Intensity of follow-up after pancreatic cancer resection. Ann Surg Oncol 21: 747-751, 2014.

10. Kalser $\mathrm{MH}$ and Ellenberg SS: Pancreatic cancer. Adjuvant combined radiation and chemotherapy following curative resection. Arch Surg 120: 899-903, 1985.

11. Bakkevold KE, Arnesjø B, Dahl O and Kambestad B: Adjuvant combination chemotherapy (AMF) following radical resection of carcinoma of the pancreas and papilla of Vater-results of a controlled, prospective, randomized multicentre study. Eur J Cancer 29A: 698-703, 1993.

12. Gastrointestinal Tumor Study Group: Further evidence of effective adjuvant combined radiation and chemotherapy following curative resection of pancreatic cancer. Cancer 59: 2006-2010, 1987.

13. Oettle H, Neuhaus P, Hochhaus A, Hartmann JT, Gellert K, Ridwelski K, Niedergethmann M, Zülke C, Fahlke J, Arning MB, et al: Adjuvant chemotherapy with gemcitabine and long-term outcomes among patients with resected pancreatic cancer: The CONKO-001 randomized trial. JAMA 310: 1473-1481, 2013.

14. Ueno H, Kosuge T, Matsuyama Y, Yamamoto J, Nakao A, Egawa S, Doi R, Monden M, Hatori T, Tanaka M, et al: A randomized phase III trial comparing gemcitabine with surgery-only in patients with resected pancreatic cancer: Japanese study group of adjuvant therapy for pancreatic cancer. Br J Cancer 101: 908-915, 2009.

15. Herman JM, Swartz MJ, Hsu CC, Winter J, Pawlik TM, Sugar E, Robinson R, Laheru DA, Jaffee E, Hruban RH, et al: Analysis of fluorouracil-based adjuvant chemotherapy and radiation after pancreaticoduodenectomy for ductal adenocarcinoma of the pancreas: Results of a large, prospectively collected database at the Johns Hopkins Hospital. J Clin Oncol 26: 3503-3510, 2008.

16. Corsini MM, Miller RC, Haddock MG, Donohue JH, Farnell MB, Magorney DM, Jatoi A, McWilliams RR, Kim GP, Bhatia S, et al: Adjuvant radiotherapy and chemotherapy for pancreatic carcinoma: The mayo clinic experience (1975-2005). J Clin Oncol 26: 3511-3516, 2008.

17. Hsu CC, Herman JM, Corsini MM, Winter JM, Callister MD, Haddock MG, Cameron JL, Pawlik TM, Schulick RD, Wolfgang CL, et al: Adjuvant chemoradiation for pancreatic adenocarcinoma: The Johns Hopkins Hospital-Mayo clinic collaborative study. Ann Surg Oncol 17: 981-990, 2010.

18. Neoptolemos JP, Stocken DD, Friess H, Bassi C, Dunn JA, Hickey H, Beger H, Fernandez-Cruz L, Dervenis C, Lacaine F, et al: A randomized trial of chemoradiotherapy and chemotherapy after resection of pancreatic cancer. $\mathrm{N}$ Engl J Med 350: 1200-1210, 2004

19. Stocken DD, Büchler MW, Dervenis C, Bassi C, Jeekel H, Klinkenbijl JH, Bakkevold KE, Takada T, Amano $\mathrm{H}$ and Neoptolemos JP; Pancreatic Cancer Meta-analysis Group: Meta-analysis of randomized adjuvant therapy trials for pancreatic cancer. Br J Cancer 92: 1372-1381, 2005.

20. Boeck S, Ankerst DP and Heinemann V: The role of adjuvant chemotherapy for patients with resected pancreatic cancer: Systematic review of randomized controlled trials and meta-analysis. Oncology 72: 314-321, 2007.

21. Butturini G, Stocken DD, Wente MN, Jeekel H, Klinkenbijl JH, Bakkevold KE, Takada T, Amano H, Dervenis C, Bassi C, et al: Influence of resection margins and treatment on survival in patients with pancreatic cancer: Meta-analysis of randomized controlled trials. Arch Surg 143: 75-83, 2008.

22. Liao WC, Chien KL, Lin YL, Wu MS, Lin JT, Wang HP and Tu YK: Adjuvant treatments for resected pancreatic adenocarcinoma: A systematic review and network meta-analysis. Lancet Oncol 14: 1095-1103, 2013.

23. Yu Z, Zhong W, Tan ZM, Wang LY and Yuan YH: Gemcitabine adjuvant therapy for resected pancreatic cancer: A meta-analysis. Am J Clin Oncol 38: 322-325, 2015.

24. Ren F, Xu YC, Wang HX, Tang L and Ma Y: Adjuvant chemotherapy, with or without postoperative radiotherapy, for resectable advanced pancreatic adenocarcinoma: Continue or stop? Pancreatology 12: 162-169, 2012.

25. Morganti AG, Falconi M, van Stiphout RG, Mattiucci GC, Alfieri S, Calvo FA, Dubois JB, Fastner G, Herman JM, Maidment BW III, et al: Multi-institutional pooled analysis on adjuvant chemoradiation in pancreatic cancer. Int J Radiat Oncol Biol Phys 90: 911-917, 2014.

26. Khanna A, Walker GR, Livingstone AS, Arheart KL, Rocha-Lima $\mathrm{C}$ and Koniaris LG: Is adjuvant 5-FU-based chemoradiotherapy for resectable pancreatic adenocarcinoma beneficial? A meta-analysis of an unanswered question. J Gastrointest Surg 10: 689-697, 2006. 
27. Klinkenbijl JH, Jeekel J, Sahmoud T, van Pel R, Couvreur ML, Veenhof CH, Arnaud JP, Gonzalez DG, de Wit LT, Hennipman A and Wils J: Adjuvant radiotherapy and 5-fluorouracil after curative resection of cancer of the pancreas and periampullary region: Phase III trial of the EORTC gastrointestinal tract cancer cooperative group. Ann Surg 230: 776-784, 1999.

28. Regine WF, Winter KA, Abrams R, Safran H, Hoffman JP, Konski A, Benson AB, Macdonald JS, Rich TA and Willett CG: Fluorouracil based chemoradiation with either gemcitabine or fluorouracil chemotherapy following resection of pancreatic adenocarcinoma: 5-year analysis of the US intergroup/RTOG 9704 phase III trial. Ann Surg Oncol 18: 1319-1326, 2011.

29. Neoptolemos JP, Stocken DD, Bassi C, Ghaneh P, Cunningham D, Goldstein D, Padbury R, Moore MJ, Gallinger S, Mariette C, et al: Adjuvant chemotherapy with fluorouracil plus folinic acid vs. gemcitabine following pancreatic cancer resection: A randomized controlled trial. JAMA 304: 1073-1081, 2010.

30. Neoptolemos JP, Stocken DD, Tudur Smith C, Bassi C, Ghaneh P, Owen E, Moore M, Padbury R, Doi R, Smith D and Büchler MW: Adjuvant 5-fluorouracil and folinic acid vs. observation for pancreatic cancer: Composite data from the ESPAC-1 and -3 (v1) trials. Br J Cancer 100: 246-250, 2009.

31. Raigani S, Ammori J, Kim J and Hardacre JM: Trends in the treatment of resectable pancreatic adenocarcinoma. J Gastrointest Surg 18: 113-123, 2014.

32. Murakami Y, Uemura K, Sudo T, Hashimoto Y, Kondo N, Nakagawa N, Sasaki H and Sueda T: Early initiation of adjuvant chemotherapy improves survival of patients with pancreatic carcinoma after surgical resection. Cancer Chemother Pharmacol 71: 419-429, 2013

33. Valle JW, Palmer D, Jackson R, Cox T, Neoptolemos JP, Ghaneh P, Rawcliffe CL, Bassi C, Stocken DD, Cunningham D, et al: Optimal duration and timing of adjuvant chemotherapy after definitive surgery for ductal adenocarcinoma of the pancreas: Ongoing lessons from the ESPAC-3 study. J Clin Oncol 32: 504-512, 2014

34. Schmidt J, Abel U, Debus J, Harig S, Hoffmann K, Herrmann T, Bartsch D, Klein J, Mansmann U, Jäger D, et al: Open-label, multicenter, randomized phase III trial of adjuvant chemoradiation plus interferon Alfa-2b versus fluorouracil and folinic acid for patients with resected pancreatic adenocarcinoma. J Clin Oncol 30: 4077-4083, 2012.

35. Fukutomi A, Uesaka K, Boku N, Kanemoto H, Konishi M, Matsumoto I, et al: JASPAC-01: Randomized phase III trial of adjuvant chemotherapy with gemcitabine versus S-1 for patients with resected pancreatic cancer. J Clin Oncol 31 (Suppl): 4008, 2013

36. Antoniou G, Kountourakis P, Papadimitriou K, Vassiliou V and Papamichael D: Adjuvant therapy for resectable pancreatic adenocarcinoma: Review of the current treatment approaches and future directions. Cancer Treat Rev 40: 78-85, 2014.

37. Evans DB, Ritch PS and Erickson BA: Neoadjuvant therapy for localized pancreatic cancer: Support is growing? Ann Surg 261: 18-20, 2015.

38. Andriulli A, Festa V, Botteri E, Valvano MR, Koch M, Bassi C, Maisonneuve P and Sebastiano PD: Neoadjuvant/preoperative gemcitabine for patients with localized pancreatic cancer: A meta-analysis of prospective studies. Ann Surg Oncol 19: $1644-1662,2012$

39. Gillen S, Schuster T, Meyer Zum Büschenfelde CM, Friess H and Kleef J: Preoperative/neoadjuvant therapy in pancreatic cancer: A systematic review and meta-analysis of response and resection percentages. PLoS Med 7: e1000267, 2010.

40. Assifi MM, Lu X, Eibl G, Reber HA, Li G and Hines OJ Neoadjuvant therapy in pancreatic adenocarcinoma: A meta-analysis of phase II trials. Surgery 150: 466-473, 2011.

41. Xu CP, Xue XJ, Liang N, Xu DG, Liu FJ, Yu XS and Zhang JD: Effect of chemoradiotherapy and neoadjuvant chemoradiotherapy in resectable pancreatic cancer: A systematic review and meta-analysis. J Cancer Res Clin Oncol 140: 549-559, 2014.

42. Abbott DE, Tzeng CW, Merkow RP, Cantor SB, Chang GJ, Katz MH, Bentrem DJ, Bilimoria KY, Crane $\mathrm{CH}$, Varadhachary GR, et al: The cost-effectiveness of neoadjuvant chemoradiation is superior to a surgery-first approach in the treatment of pancreatic head adenocarcinoma. Ann Surg Oncol 20 (Suppl 3): S500-S508, 2013.

43. Cooper AB, Parmar AD, Riall TS, Hall BL, Katz MH, Aloia TA and Pitt HA: Does the use of neoadjuvant therapy for pancreatic adenocarcinoma increase postoperative morbidity and mortality rates? J Gastrointest Surg 19: 80-87, 2015.
44. Golcher H, Brunner TB, Witzigmann H, Marti L, Bechstein W, Bruns C, Jungnickel H, Schreiber S, Grabenbauer GG, Meyer T, et al: Neoadjuvant chemoradiation therapy with gemcitabine/cisplatin and surgery versus immediate surgery in resectable pancreatic cancer: Results of the first prospective randomized phase II trial. Strahlenther Onkol 191: 7-16, 2015.

45. Bond-Smith G, Banga N, Hammond TM and Imber CJ: Pancreatic adenocarcinoma. BMJ 344: e2476, 2012.

46. Varadhachary GR, Tamm EP, Abbruzzese JL, Xiong HQ, Crane CH, Wang H, Lee JE, Pisters PW, Evans DB and Wolff RA: Borderline resectable pancreatic cancer: Definitions, management and role of preoperative therapy. Ann Surg Oncol 13: 1035-1046, 2006.

47. Morganti AG, Massaccesi M, La Torre G, Caravatta L, Piscopo A, Tambaro R, Sofo L, Sallustio G, Ingrosso M, Macchia G, et al: A systematic review of resectability and survival after concurrent chemoradiation in primarily unresectable pancreatic cancer. Ann Surg Oncol 17: 194-205, 2010.

48. Laurence JM, Tran PD, Morarji K, Eslick GD, Lam VW and Sandroussi C: A systematic review and meta-analysis of survival and surgical outcomes following neoadjuvant chemoradiotherapy for pancreatic cancer. J Gastrointest Surg 15: 2059-2069, 2011.

49. Petrelli F, Coinu A, Borgonovo KF, Ghilardi M, Cabiddu M, Cremonesi M, Lonati V and Barni S: Resection rate with FOLFIRINOX-based neoadjuvant therapy in locally advanced/borderline resectable pancreatic cancer: A pooled analysis of published data. Ann Oncol 25 (Suppl 4): iv240, 2014.

50. Katz MHG, Crane CH and Varadhachary G: Management of borderline resectable pancreatic cancer. Semin Radiat Oncol 24: 105-112, 2014.

51. Lopez NE, Prendergast C and Lowy AM: Borderline resectable pancreatic cancer: Definitions and management. World J Gastroenterol 20: 10740-10751, 2014.

52. Katz MHG, Fleming JB, Bhosale P, Varadhachary G, Lee JE, Wolff R, Wang H, Abbruzzese J, Pisters PW, Vauthey JN, et al: Response of borderline resectable pancreatic cancer to neoadjuvant therapy is not reflected by radiographic indicators. Cancer 118: 5749-5756, 2012

53. Festa V, Andriulli A, Valvano MR, Uomo G, Perri F, Andriulli N, Corrao $\mathrm{S}$ and Koch M: Neoadjuvant chemoradiotherapy for patients with borderline resectable pancreatic cancer: A meta-analytical evaluation of prospective studies. JOP 14: 618-625, 2013.

54. Seufferlein T, Laethem JLV, Cutsem EV, Berlin JD, Büchler M, Cervantes A, et al: The management of locally advanced pancreatic cancer: European Society of Digestive Oncology (ESDO) expert discussion and recommendations from the $14^{\text {th }}$ ESMO/World Congress on Gastrointestinal Cancer, Barcelona. Ann Oncol 25 (Suppl 2): iil-ii4, 2014

55. Ferrone CR, Marchegiani G, Hong TS, Ryan DP, Deshpande V, McDonnell EI, Sabbatino F, Santos DD, Allen JN, Blaszkowsky LS, et al: Radiological and surgical implications of neoadjuvant treatment with FOLFIRINOX for locally advanced and borderline resectable pancreatic cancer. Ann Surg 261: $12-17,2015$

56. Gurusamy KS, Kumar S, Davidson BR and Fusai G: Resection versus other treatments for locally advanced pancreatic cancer. Cochrane Database Syst Rev 2: CD010244, 2014

57. Mollberg N, Rahbari NN, Koch M, Hartwig W, Hoeger Y, Büchler MW and Weitz J: Arterial resection during pancreatectomy for pancreatic cancer: A systematic review and meta-analysis. Ann Surg 254: 882-893, 2011.

58. Sultana A, Smith CT, Cunningham D, Starling N, Neoptolemos JP and Ghaneh P: Meta-analyses of chemotherapy for locally advanced and metastatic pancreatic cancer. J Clin Oncol 25: 2607-2615, 2007.

59. Burris HA, Moore MJ, Andersen J, Green MR, Rothenberg ML, Modiano MR, Cripps MC, Portenoy RK, Storniolo AM, Tarassoff $\mathrm{P}$, et al: Improvements in survival and clinical benefit with gemcitabine as first-line therapy for patients with advanced pancreas cancer: A randomized trial. J Clin Oncol 15: 2403-2413, 1997.

60. Liang HL: Comparing gemcitabine-based combination chemotherapy with gemcitabine alone in inoperable pancreatic cancer: A meta-analysis. J Clin Oncol 23: 4110, 2005.

61. Xie DR, Liang HL, Wang Y and Guo SS: Meta-analysis of inoperable pancreatic cancer: Gemcitabine combined with cisplatin versus gemcitabine alone. Chin J Dig Dis 7: 49-54, 2006. 
62. Sultana A, Tudur Smith C, Cunningham D, Starling N, Neoptolemos JP and Ghaneh P: Meta-analyses of chemotherapy for locally advanced and metastatic pancreatic cancer: Results of secondary end points analyses. Br J Cancer 99: 6-13, 2008.

63. Xie DR, Liang HL, Wang Y, Guo SS and Yang Q: Meta-analysis on inoperable pancreatic cancer: A comparison between gemcitabine-based combination therapy and gemcitabine alone. World J Gastroenterol 12: 6973-6981, 2006.

64. Bria E, Milella M, Gelibter A, Cuppone F, Pino MS, Ruggeri EM, Carlini P, Nisticò C, Terzoli E, Cognetti F and Giannarelli D: Gemcitabine-based combinations for inoperable pancreatic cancer: Have we made real progress? A meta-analysis of 20 phase 3 trials. Cancer 110: 525-533, 2007.

65. Hu J, Zhao G, Wang HX, Tang L, Xu YC, Ma Y and Zhang FC: A meta-analysis of gemcitabine containing chemotherapy for locally advanced and metastatic pancreatic adenocarcinoma. J Hematol Oncol 4: 11, 2011.

66. Sun C,AnsariD, Andersson R and Wu DQ: Does gemcitabine-based combination therapy improve the prognosis of unresectable pancreatic cancer? World J Gastroenterol 18: 4944-4958, 2012

67. Li Q, Yan H, Liu W, Zhen H, Yang Y and Cao B: Efficacy and safety of gemcitabine-fluorouracil combination therapy in the management of advanced pancreatic cancer: A meta-analysis of randomized controlled trials. PLoS One 9: e104346, 2014.

68. Heinemann V, Labianca R, Hinke A and Louvet C: Increased survival using platinum analog combined with gemcitabine as compared to single-agent gemcitabine in advanced pancreatic cancer: Pooled analysis of two randomized trials, the GERCOR/GISCAD intergroup study and a German multicenter study. Ann Oncol 18: 1652-1659, 2007.

69. Banu E, Banu A, Fodor A, Landi B, Rougier P, Chatellier G, Andrieu JM and Oudard S: Meta-analysis of randomized trials comparing gemcitabine-based doublets versus gemcitabine alone in patients with advanced and metastatic pancreatic cancer. Drugs Aging 24: 865-879, 2007.

70. Heinemann V, Boeck S, Hinke A, Labianca R and Louvet C: Meta-analysis of randomized trials: Evaluation of benefit from gemcitabine-based combination chemotherapy applied in advanced pancreatic cancer. BMC Cancer 8: 82, 2008.

71. Cunningham D, Chau I, Stocken DD, Valle JW, Smith D, Steward W, Harper PG, Dunn J, Tudur-Smith C, West J, et al: Phase III randomized comparison of gemcitabine versus gemcitabine plus capecitabine in patients with advanced pancreatic cancer. J Clin Oncol 27: 5513-5518, 2009

72. Xie DR, Yang Q, Chen DL, Jiang ZM, Bi ZF, Ma W and Zhang YD: Gemcitabine-based cytotoxic doublets chemotherapy for advanced pancreatic cancer: Updated subgroup meta-analysis of overall survival. Jpn J Clin Oncol 40: 432-441, 2010.

73. Ciliberto D, Botta C, Correale P, Rossi M, Caraglia M, Tassone P and Tagliaferri P: Role of gemcitabine-based combination therapy in the management of advanced pancreatic cancer: A meta-analysis of randomized trials. Eur J Cancer 49: 593-603, 2013.

74. Eltawil KM, Renfrew PD and Molinari M: Meta-analysis of phase III randomized trials of molecular targeted therapies for advanced pancreatic cancer. HPB (Oxford) 14: 260-268, 2012.

75. Tian W, Ding W, Kim S, Xu X, Pan M and Chen S: Efficacy and safety profile of combining agents against epidermal growth factor receptor or vascular endothelium growth factor receptor with gemcitabine-based chemotherapy in patients with advanced pancreatic cancer: A meta-analysis. Pancreatology 13: 415-422, 2013.

76. Chen L, Zhang M and Luo S: Outcome of gemcitabine plus molecular targeted agent for treatment of pancreatic cancer: A meta-analysis of prospective phase III studies. Tumor Biol 35: $11551-11558,2014$

77. Li Q, Yuan Z, Yan H, Wen Z, Zhang R and Cao B: Comparison of gemcitabine combined with targeted agent therapy versus gemcitabine monotherapy in the management of advanced pancreatic cancer. Clin Ther 36: 1054-1063, 2014.

78. Van Loon K, Espinoza AM, Fogeman DR, Wolff RA, Javle MM, Iyer RV, Picozzi VJ, Martin LK, Bekaii-Saab T, Tempero MA, et al: Should combination chemotherapy serve as the backbone in clinical trials of advanced pancreatic cancer?: A pooled analysis of phase II trials of gemcitabine-containing doublets plus bevacizumab. Pancreas 43: 343-349, 2014

79. Yanagimoto H, Ishii H, Nakai Y, Ozaka M, Ikari T, Koike K, Ueno $\mathrm{H}$, Ioka $\mathrm{T}$, Satoi $\mathrm{S}$, Sho M, et al: Improved survival with combined gemcitabine and S-1 for locally advanced pancreatic cancer: Pooled analysis of three randomized studies. J Hepatobiliary Pancreat Sci 21: 761-766, 2014.
80. Ku GY, Haaland BA, Ioka T, Isayama H, Nakai Y, Cheng AL, Okusaka T and de Lima Lopes Jr G: Meta-analysis of randomized phase II and phase III trials of gemcitabine with/without S-1 in Asian patients with advanced pancreatic cancer. Revista Brasileira de Oncologia Clínica 10: 10-16, 2014.

81. Liu Y, Huang QK, Hong WD, Wu JM and Sun XC: The addition of S-1 to gemcitabine-based chemotherapy improves survival with increased toxicity for patients with advanced pancreatic cancer: Combined meta-analysis of efficacy and safety profile. Clin Res Hepatol Gastroenterol 39: 254-260, 2015.

82. Sultana A, Ghaneh P, Cunningham D, Starling N, Neoptolemos JP and Smith CT: Gemcitabine based combination chemotherapy in advanced pancreatic cancer-indirect comparison. BMC Cancer 8: 192,2008 .

83. Faris JE, Blaszkowsky LS, McDermott S, Guimaraes AR, Szymonifka J, Huynh MA, Ferrone CR, Wargo JA, Allen JN, Dias LE, et al: FOLFIRINOX in locally advanced pancreatic cancer: The Massachusetts General Hospital Cancer Center experience. Oncologist 18: 543-548, 2013.

84. Huguet F, Mukherjee S and Javle M: Locally advanced pancreatic cancer: The role of definitive chemoradiotherapy. Clin Oncol (R Coll Radiol) 26: 560-568, 2014.

85. Tempero MA, Malafa MP, Behrman SW, Benson AB III, Casper ES, Chiorean EG, Chung V, Cohen SJ, Czito B, Engebretson A, et al: Pancreatic adenocarcinoma, Version 2.2014: Featured updates to the NCCN guidelines. J Natl Compr Canc Netw 12: 1083-1093, 2014.

86. Xie J, Yuan J and Lu L: Gemcitabine fixed-dose rate infusion for the treatment of pancreatic carcinoma: A meta-analysis of randomized controlled trials. Diagn Pathol 9: 214, 2014

87. Liu F, Tang Y, Sun J, Yuan Z, Li S, Sheng J, Ren H and Hao J: Regional intra-arterial vs. systemic chemotherapy for advanced pancreatic cancer: A systematic review and meta-analysis of randomized controlled trials. PLoS One 7: e40847, 2012.

88. Hong GB, Zhou JX, Xu LF, Luo FT, Jang RJ, Luo JH and Chen YT: Meta-analysis on comparative study of curative effect between interventional therapy and conventional systemic venous chemotherapy in moderate and advanced pancreatic cancer. J Pract Radiol 4: 022, 2004.

89. Rombouts SJ, Vogel JA, van Santvoort HC, van Lienden KP, van Hillegersberg R, Busch OR, Besselink MG and Molenaar IQ: Systematic review of innovative ablative therapies for the treatment of locally advanced pancreatic cancer. Br J Surg 102: 182-193, 2015.

90. Moertel CG, Frytak S, Hahn RG, O'Connell MJ, Reitemeier RJ, Rubin J, Schutt AJ, Weiland LH, Childs DS, Holbrook MA, et al: Therapy of locally unresectable pancreatic carcinoma: A randomized comparison of high dose (6000 rads) radiation alone, moderate dose radiation (4000 rads +5 -fluorouracil) and high dose radiation +5 -fluorouracil: The Gastrointestinal Study Group. Cancer 48: 1705-1710, 1981.

91. Hazel JJ, Thirlwell MP, Huggins M, Maksymiuk A and MacFarlane JK: Multi-drug chemotherapy with and without radiation for carcinoma of the stomach and pancreas: A prospective randomized trial. J Can Assoc Radiol 32: 164-165, 1981.

92. Klaassen DJ, MacIntyre JM, Catton GE, Engstrom PF and Moertel CG: Treatment of locally unresectable cancer of the stomach and pancreas: A randomized comparison of 5-fluorouracil alone with radiation plus concurrent and maintenance 5-fluorouracil-an Eastern Cooperative Oncology Group study. J Clin Oncol 3: 373-378, 1985.

93. Treatment of locally unresectable carcinoma of the pancreas: Comparison of combined-modality therapy (chemotherapy plus radiotherapy) to chemotherapy alone. Gastrointestinal Tumor Study Group. J Natl Cancer Inst 80: 751-755, 1988.

94. Cohen SJ, Dobelbower R Jr, Lipsitz S, Catalano PJ, Sischy B, Smith TJ and Haller DG; Eastern Cooperative Oncology Group: A randomized phase III study of radiotherapy alone or with 5-fluorouracil and mitomycin-C in patients with locally advanced adenocarcinoma of the pancreas: Eastern Cooperative Oncology Group study E8282. Int J Radiat Oncol Biol Phys 62: 1345-1350, 2005.

95. Loehrer PJ, Feng Y, Cardenes H, Wagner L, Brell JM, Cella D, Flynn P, Ramanathan RK, Crane CH, Alberts SR and Benson AB III: Gemcitabine alone versus gemcitabine plus radiotherapy in patients with locally advanced pancreatic cancer: An Eastern Cooperative Oncology Group trial. J Clin Oncol 29: 4105-4112, 2011. 
96. Chauffert B, Mornex F, Bonnetain F, Rougier P, Mariette C, Bouché O, Bosset JF, Aparicio T, Mineur L, Azzedine A, et al: Phase III trial comparing intensive induction chemoradiotherapy (60 Gy, infusional 5-FU and intermittent cisplatin) followed by maintenance gemcitabine with gemcitabine alone for locally advanced unresectable pancreatic cancer. Definitive results of the 2000-01 FFCD/SFRO study. Ann Oncol 19: 1592-1599, 2008.

97. Sultana A, Tudur Smith C, Cunningham D, Starling N, Tait D, Neoptolemos JP and Ghaneh P: Systematic review, including meta-analyses, on the management of locally advanced pancreatic cancer using radiation/combined modality therapy. Br J Cancer 96: 1183-1190, 2007.

98. Huguet F, Girard N, Guerche CS, Henneguin C, Mornex F and Azria D: Chemoradiotherapy in the management of locally advanced pancreatic carcinoma: A qualitative systematic review. J Clin Oncol 27: 2269-2277, 2009.

99. Chen Y, Sun XJ, Jiang TH and Mao AW: Combined radiochemotherapy in patients with locally advanced pancreatic cancer: A meta-analysis. World J Gastronterol 19: 7461-7471, 2013.

100. Bernstein M, Kaubisch A, Rosenstein M, Aparo S, Garg MK, Kalnicki S, Guha C and Ohri N: Chemotherapy alone versus chemoradiation for unresectable pancreatic cancer: A meta-analysis. Int J Radiat Oncol Biol Phys 90 (Suppl 2014): S363-S364, 2014.

101.Zhang X, Huang HJ, Feng D, Yang DJ, Wang CM and Cai QP: Is concomitant radiotherapy necessary with gemcitabine-based chemotherapy in pancreatic cancer? World J Gastroenterol 20: 17648-17655, 2014.

102.Zhu CP, Shi J, Chen YX, Xie WF and Lin Y: Gemcitabine in the chemoradiotherapy for locally advanced pancreatic cancer: A meta-analysis. Radiother Oncol 99: 108-113, 2011.

103. Huguet F, André T, Hammel P, Artru P, Balosso J, Selle F, Deniaud-Alexandre E, Ruszniewski P, Touboul E, Labianca R, et al: Impact of chemoradiotherapy after disease control with chemotherapy in locally advanced pancreatic adenocarcinoma in GERCOR phase II and III studies. J Clin Oncol 25: 326-331, 2007.

104.Ko AH, Quivey JM, Venook AP, Bergsland EK, Dito E, Schillinger B and Tempero MA: A phase II study of fixed-dose rate gemcitabine plus low-dose cisplatin followed by consolidative chemoradiation for locally advanced pancreatic cancer. Int J Radiat Oncol Biol Phys 68: 809-816, 2007.

105.Krishnan S, Rana V, Janjan NA, Varadhachary GR, Abbruzzese JL, Das P, Delclos ME, Gould MS, Evans DB, Wolff RA and Crane $\mathrm{CH}$ : Induction chemotherapy selects patients with locally advanced, unresectable pancreatic cancer for optimal benefit from consolidative chemoradiation therapy. Cancer 110: 47-55, 2007.

106. Hammel P, Huguet F, Van Laethem JL, Goldstein D, Glimelius B, Artru P, et al: Comparison of chemoradiotherapy (CRT) and chemotherapy $(\mathrm{CT})$ in patients with a locally advanced pancreatic cancer (LAPC) controlled after 4 months of gemcitabine with or without erlotinib: Final results of the international phase III LAP 07 study. J Clin Oncol 31 (Suppl): LBA4003, 2013.
107. Murphy JD, Chang DT, Abelson J, Daly ME, Yeung HN, Nelson LM and Koong AC: Cost-effectiveness of modern radiotherapy techniques in locally advanced pancreatic cancer. Cancer 118: 1119-1129, 2012

108. Fung MC, Takayama S, Ishiguro H, Sakata T, Adachi $S$ and Morizane T: Chemotherapy for advanced or metastatic pancreatic cancer: Analysis of 43 randomized trials in 3 decades (1974-2002). Gan To Kagaku Ryoho 30: 1101-1111, 2003 (In Japanese).

109. Moore MJ, Goldstein D, Hamm J, Figer A, Hecht JR, Gallinger S, Au HJ, Murawa P, Walde D, Wolff RA, et al: Erlotinib plus gemcitabine compared with gemcitabine alone in patients with advanced pancreatic cancer: A phase III trial of the National Cancer Institute of Canada Clinical Trials Group. J Clin Oncol 25: 1960-1966, 2007.

110. Yang ZY, Yuan JQ, Di MY, Zheng DY, Chen JZ, Ding H, Wu XY, Huang YF, Mao C and Tang JL: Gemcitabine plus erlotinib for advanced pancreatic cancer: A systematic review with meta-analysis. PLoS One 8: e57528, 2013.

111. Ueno H, Ioka T, Ikeda M, Ohkawa S, Yanagimoto H, Boku N, Fukutomi A, Sugimori K, Baba H, Yamao K, et al: Randomized phase III study of gemcitabine plus S-1, S-1 alone, or gemcitabine alone in patients with locally advanced and metastatic pancreatic cancer in Japan and Taiwan: GEST study. J Clin Oncol 31: 1640-1648, 2013.

112. Conroy T, Desseigne F, Ychou M, Bouché O, Guimbaud R, Bécouarn Y, Adenis A, Raoul JL, Gourgou-Bourgade S, de la Fouchardière $\mathrm{C}$, et al: FOLFIRINOX versus gemcitabine for metastatic pancreatic cancer. N Engl J Med 364: 1817-1825, 2011.

113. Von Hoff DD, Ervin T, Arena FP, Chiorean EG, Infante J, Moore M, Seay T, Tjulandin SA, Ma WW, Saleh MN, et al: Increased survival in pancreatic cancer with nab-paclitaxel plus gemcitabine. N Engl J Med 369: 1691-1703, 2013.

114. Chan K, Shah K, Lien K, Coyle D, Lam H and Ko YJ: A Bayesian meta-analysis of multiple treatment comparisons of systemic regimens for advanced pancreatic cancer. PLoS One 9: e108749, 2014.

115. Gresham GK, Wells GA, Gill S, Cameron C and Jonker DJ: Chemotherapy regimens for advanced pancreatic cancer: A systematic review and network meta-analysis. BMC Cancer 14: 471, 2014.

116. Petrelli F, Coinu A, Borgonovo K, Cabiddu M, Ghilardi M and Barni S: Polychemotherapy or gemcitabine in advanced pancreatic cancer: A meta-analysis. Dig Liver Dis 46: 452-459, 2014.

117. Attard CL, Brown S, Alloul K and Moore MJ: Cost-effectiveness of FOLFIRINOX for first-line treatment of metastatic pancreatic cancer. Curr Oncol 21: e41-e51, 2014. 